\title{
Kentsel Marjinallik ve Devletin Sağ Eli ${ }^{1}$
}

\section{Urban Marginality and the Right Hand of the State}

Loïc Wacquant ve Aksu Akçaoğlu

UC Berkeley -Çanakkale Onsekiz Mart Üniversitesi

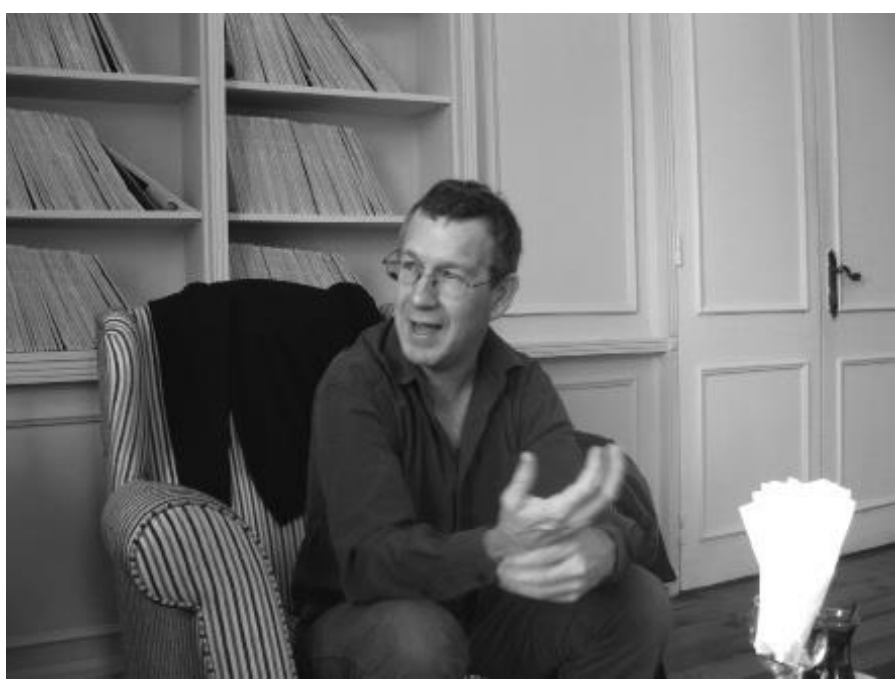

Fotoğraf: Ekin Ekici

Aksu Akçaoğlu (AA): Kent Paryalari'nda (2015) 1980'lerde yeni bir kentsel marjinallik rejiminin doğduğunu ileri sürüyorsunuz. İçinde bulunduğumuz bu yeni dönemin ayırt edici özellikleri nelerdir?

Loïc Wacquant (LW): Çalışmamın başlangıç noktasında kentsel yoksulluk ve toplumsal hareketlilik çalışmalarının eleştirisi bulunuyor. Bu araştırmalarda yoksulluğun geride bıraktığımız, kabaca 1880-1980 arasını kapsayan, Fordist ekonomi-Keynesçi refah devleti yüzyılına ait fikirler,

\footnotetext{
${ }^{1}$ Bu söyleşi, Lö̈c Wacquant 17 Ocak 2014'te Hrant Dink Insan Hakları ve Ifade Özgürlüğ̈̈ Konferansi'nda konuşmacı olarak Türkiye'ye geldiğginde, Boğaziçi Üniversitesi'nde gerçekleştirilmiştir ve Birikim' in Şubat 2014'teki 298. sayısında yayımlanmıştır. Bkz. Akçaoğlu, A. (2014) “Loïc Wacquant'la Söyleşi: Kentsel Marjinalleşme ve Devletin Sağ Eli”. Birikim 298: 67-72. Söyleşi, temayla olan yakın ilişkisi nedeniyle tekrar basılmıştır. Burada yeniden yayımlanmasına izin veren Tanıl Bora ve Birikim ekibine teşekkürü borç bilirim [AA].
}

idealkent @ Kent Araştırmaları Dergisi (Journal of Urban Studies)

http://idealkentdergisi.com

Geliş Tarihi Received Date: 16.02.2019 Kabul Tarihi Accepted Date: 11.04.2019 
kategoriler ve bakış açılarıyla tanımlandığını görüyoruz. Geride bıraktığımız yüzyılda yoksulluk, büyük bir oranda, iş yetersizliğinden kaynaklanmaktaydı. Yoksullukla mücadele ise yeni fabrikaların açılmasını gerektiriyordu. Bu mücadeleyi de refah devleti veriyordu. Dolayısiyla, Fordist ekonomi ve Keynesçi refah devleti arasında önemli oranda uyum vardı. Özellikle gelişmiş yeteneklerden mahrum kesimler için hayat istikrarının, gelecek tasarılarının ve hane halkının yeniden üretiminin merkezinde yer alan ekonomik alan, fabrika işçiliğine ve benim 40-50-60 formülü olarak adlandırdığım, 60 yaşına kadar yılda 50 hafta, haftada 40 saat çalışma ilkesine dayanıyordu. Bu ekonomik sistem, kendi döngüsüyle uyumlu, gelirin bir kısmının yeniden dağıtımını ve vatandaşların sosyal güvenliğini görev edinmiş Kesnesgil refah devletinin oluşumuyla da bağlantılıdır. Ekonomi çöktügün̈nde devlet koruma politikalarını devreye sokar, işler yoluna girdiğinde geri çekilir; Fordist ekonomi ve Keynesçi refah devleti uyumundan bahsettiğimde kast ettiğim budur.

Ekonomi ve devlet uyumunun parçası olmakla birlikte, üzerinde pek de durulmayan iki unsur daha var. Bunlardan ilki, erkeğin aile reisi olduğu, kadınınsa emeğini hane halkının ve dolayısıyla çalışmanın, fabrikanın ve toplumun yeniden üretimine adadığı erkek egemen çekirdek ailedir. İkincisi ve en az inceleneni ise yaştır. Geçtiğimiz yüzyılda yaşın etkisi bugüne kıyasla daha sert hissediliyordu. 16 yaşına kadar okula gidiliyor, hemen arkasından fabrikada işe giriliyor ve yine belirli bir yaşta aile kuruluyordu. Burada temel hatlarını çizdiğim Fordist-Keynesçi yüzyılla kusursuz uyum içinde olan bir toplum yoktur. Benim burada yaptığım, sanayi toplumlarının büyük bir kısmında, farklı biçimlerde de olsa, gözlemlenen bir ideal-tip kurmaktan ibaret.

1970'lere ve 80'lere geldiğimizde sözünü ettiğimiz bu uyumun parçalandığını, 40-50-60 formülünün yerini formülsüzlüğe bıraktığını görüyoruz. Sanayi sonrası toplumun işçi sınıfı için, özellikle de vasıfsız kesimler için, işi örgütleyen bir ilkeden söz etmek mümkün değil. Artık tek formülün yerini çok formüle bıraktı̆̆ 1 bir duruma geçiyoruz. Ücretli emeğin parçalandığını, daha önce birbirine benzeyen hayat deneyimlerinin farklılaştı̆̆ını gözlemliyoruz. Durkheim'ın kavram setinden hareketle, önceki yüzyılın benzer iş deneyimlerinin, işçileri mekanik dayanışma etrafında bir araya getirdiğini söyleyebiliriz. Aynı rolleri oynadığın, aynı deneyimi paylaştı̆̆ın ve özdeşleştiğin insanlarla işçi sınıfı mahallesinde yaşamak yapısal olarak ortak kimliğin koşullarını inşa eder. Bu koşullar aynı zamanda refah devletinin de koşullarıdır. 
Öyleyse, siyasi, teknolojik, küresel vb. etkiler sonucunda emek piyasasının denetimsizleşmesiyle birlikte, daha önce aynılaştırıcı güç üreten ücretli emeğin güvensizlik, istikrasızlık, farklılaşma ve dağılma ürettiğini gözlemliyoruz. Ücretli emeğin parçalara ayrılmasıyla çalışma hayatı farkl1laşıyor. Yarı- zamanlı işler ve tam-zamanlı işler ayrımı ortaya çıkıyor; yarızamanlı işler de kendi içinde farklılaşıyor, haftada 10 saat çalışılan işler ya da 30 saat çalışılan işler gibi. Bazı işler sağlık güvencesi sağlarken, bazıları sağlamıyor. Dolayısıyla ortaya öyle bir farklılaşma çıkıyor ki; birbiriyle arkadaş otuz kişinin çalışma hayatını düzenleyen otuz ayrı formül olduğunu görüyoruz. Günümüzde ücretli emekten kaynaklanan aynılaştırıcı gücün ürettiği ortak kimlik ve siyasetten söz etmemiz mümkün değil.

AA: 1980 sonrası gözlemlenen yeni koşulları neoliberalizme bağlamak konusunda fikir birliğinden söz edebiliriz. Fakat neoliberalizm ne kadar çok çalışılırsa o kadar çok bulamıklaşıyor gibi hissediyorum. Siz çalışmalarınızda neoliberalizmi saf bir ekonomik sistem olarak kavramlaştıramayacă̆ımızı ileri sürüyorsunuz. Yeni kent marjinalliğinin üretiminde etkili olan neoliberalizm nedir ve nasıl etki eder?

LW: Aslında yukarıda ücretli emek üzerinden anlatmaya çalıştığım ekonomik alandaki dönüşümler devlete içkin çatışmalarla, bürokratik alanda verilen, devletin sağ eliyle sol eli arasındaki, mücadelelerle yakından ilişkilidir. İçinde yaşadığımız koşullar, ekonomik rekabetin uluslararasılaşması, üretimin küreselleşmesi gibi sebeplerle devlet formları arasındaki ilişkilerde de geçişin yaşandığı koşullar. Örneğin, bu dönemde Avrupa Birliği $(\mathrm{AB})$ gibi uluslararası bir koalisyonun doğuşuna tanıklık ettik. Burada kabaca temel hatlarını verdiğim bürokratik alandaki bu yeni çatışmalar, Keynesçi refah devletinden neoliberal devlete geçişin önünü açıyor. Pek çok araştırmacı için neoliberalizm, piyasa hükümranlığını ya da devletin geri çekilmesini, küçülmesini ifade ediyor. Bence sözünü ettiğimiz bu özellikler neoliberalizmin ideolojisidir. Neoliberalizmin gerçekliği ise devletin geri çekilmesinden ziyade yeniden yapilanması ve yeniden düzenlenmesiyle ilişkilidir. Metalaşmayı teşvik eden, piyasayı destekleyen bir devlet biçiminin yapılandırılmasından söz ediyoruz.

Polanyi, piyasanın doğal bir kurum olmadığını, bir kurgu olduğunu ileri sürer. Buradaki önemli nokta, piyasayı üretenin devlet olmasıdır. Öyleyse, neoliberal devlet küçülen, daralan zayıf bir devlet değildir, gücünü metalaşmayı desteklemek için kullanan güçlü bir devlet biçimidir. 
Fakat devlet metalaşmayı desteklediğinde toplumsal istikrarı riske atar. Çünkü ücretli emeğin parçalanmasını, yani yarı-zamanlı, güvencesiz, hakkaniyetsiz çalışma koşullarını normalleştirir. Bu, işçi sınıfının en vasıfsız kesimleri için güvencesiz bir hayatın normalleşmesi, hanede ve mahallede düzensizliğin hâkim olması ve kayıt dişı ekonominin büyümesi anlamına gelir. Sonuç olarak, toplumsal kargaşanın yoğunlaştığ kent çeperlerinin ve sol siyasetin güçlü olduğu eski işçi sınıfı mahallelerinin sorunlu mahallelere dönüştürüldüğünü görürüz. Türkiye'de gecekondudan varoşa geçişin, bunun örneği olduğunu düşünüyorum. Sözünü ettiğimiz bu toplumsal kargaşa, aslında metalaşmayı teşvik eden, güvencesiz hayatı normalleştiren neoliberal devlet ile ücretli emek arasındaki yeni bir ilişki biçiminin ifadesiyken, varoşlardan kaynaklanan, orada yaşayan insanlara özgü sorunlar olarak görülür. Toplumsal kargaşa belirli mahallelere hapsedilerek çözülmeye çalışılır. Neoliberal devlet bu çözümü koruyucu toplumsal refahtan disipline edici çalışma toplumuna geçerek üretir. Dolayısıyla, ben neoliberalizmi bir ekonomik rejim olarak değil, bir devlet biçimi olarak ele alıyorum.

AA: Devletteki sözünü ettiğiniz bu değişim ya da yeniden yapılanma bir sembolik sermaye arayışı olarak değerlendirilebilir mi?

LW: Bir anlamda böyle görülebilir. Temel neden, insanları bu güvencesiz koşulları kabule zorlamaktır. Devlet, toplumsal ve ekonomik güvence sağlamadığı koşullarda otoritesini yeniden sağlamlaştırmak zorundadır. Bu yeni koşullarda siyasi elitler meşruiyet açığı sıkıntısı çekiyor. Sermayenin hükümranlığını ilan ettiği koşullarda devlet iktidarını nasıl sahneler? Bütçenizi AB belirlerken, ekonomik sermaye akışı sizi gereksiz k1larken, vatandaşlarınıza iktidarda olduğunuzu nasıl anlatabilirsiniz? Devlet iktidar kapasitesini yeniden canlandırmak için ceza devletini etkin hale getirir. Polisin, mahkemelerin ve hapishanelerin etkinleşmesi benim Karl Polanyi ve Carl Schmitt problemleri olarak adlandırdığım iki sorunun çözümüne olanak sağlar. Polanyi bize şunu öğretti; toprağı, parayı, emeği metalaştırdığınızda toplumsal ilişkileri erozyona uğratırsınız. Toplumsal düzensizlik ve kargaşa yaratırsınız. Toplum da buna tepki verir.

Polanyi (2000) Büyük Dönüşüm adlı kitabında ikili hareketlerden söz eder: Piyasa hareketleri ve toplumsal ilişkileri korumak amaciyla piyasaya dur diyen karşı hareketler. Nancy Fraser (2013) gibi neoliberal çağ1 yeni karşı hareketler etrafında açıklamaya çalışanlara cevaben benim 
tezim şu: Evet karşı hareketler var ama kaynağı toplumun alt katmanları değil, devletin içi. Bourdieu'nün (1991) kavram setinden hareketle, bu karşı hareketler devletin sağ elinin verdiği tepkidir. Bu kavramsal çerçeve içinde devletin sol eli ekonomik ve kültürel sermaye yoksunu kesimlere yardım eden, koruyucu bir eldir. Sağlık, eğitim ve konut gibi, korunmaya muhtaç vatandaşlara güvence sağlamayı amaçlayan, tüm kamu politikaları devletin sol elini temsil eder. Metalaşmanın faili olan ve yeni baskılar üreten piyasa, ekonomi bakanlığı ve hazine gibi kurumlar ise devletin sağ elidir. Punishing the Poor (2009) adlı kitabımda ben bu sağ ele polisi, mahkemeleri ve hapishaneleri de ekliyorum. Sözünü ettiğim bu üç kurum, ücretli emeğin parçalanması ve devlet desteğiyle şiddetlenen metalaşmanın yol açtığ toplumsal düzensizliği mekânsal hiyerarşinin dibindeki mahallelere hapsederek tepki veren devletin sağ elidir; aynı zamanda karşı hareketlerin devlet içindeki kaynağıdır. Ceza devletinin toplumsal sorunları çözmek yerine, toplumsal ve fiziksel uzama hapsederek Karl Polanyi problemini çözüme kavuşturduğunu ileri sürüyorum.

Ceza devleti Carl Schmitt problemini de çözümler. Schmitt (2007), siyaset kavramının özünün biz ve onlar, dost ve düşman gibi ayrımlar ve sinırlar yaratmak olduğunu ileri sürer. Bir başka deyişle, bu sınırlar siyasetin başladığı noktadır. Schmitt'in haklı olduğunu düşünüyorum ve sinırlar çizip, düşman belirlemenin devletin sağ elinin ürünü olduğunu ileri sürüyorum. Sermayenin küreselleştiği koşullarda düşmanın yaban$\mathrm{Cl}$, toplum dışı bir unsur olması güçleşir. Fransa ve Almanya neredeyse tek bir ekonomiyi andıracak kadar güçlü ticari ilişkiler kurmuşken, birbirlerine muhtaçken, düşman olmaları zordur. Dolayısıyla düşman artık dışarıda değil içeride üretilir. Ceza devletinin temel olarak üç ayrım etrafında iç düşman tanımladığını ileri sürüyorum: Vatandaşa karşı yabancı, üretken vatandaşa karşı sosyal yardıma muhtaç vatandaş ve yasalara sadık vatandaşa karşı suçlular. Bu üç ayrımın birbirine çok yakın ilişkilerle bağlı olduğunu düşünüyorum. Yabancı aynı zamanda suça ve ihtiyaç duymadığı halde sosyal yardım kurumlarını sömürmeye yatkın olarak temsil edilir. Aynı şekilde, suçlu temsili de göçmen ya da yabancı temsiliyle örtüşür. Özellikle Doğu Avrupa'daki Romanların temsilini düşünün; suça ve sosyal devleti sömürmeye yatkın olarak temsil edilirler.

Her yerde, buna benzer içerideki bir yabancı unsur olarak halk düşmanları temsiliyle karşılaşabiliriz. Nazi Almanya'sında halk düşmanı olarak temsil edilen Yahudiler, zengin olarak bilinmeleri bir kenara bira- 
kılırsa, pek çok açıdan bugün Avrupa'daki Romanların temsiliyle benzeşir. Aslına bakarsanız Romanların dilencilik şebekeleri sayesinde zenginlik edindiklerine dair efsaneler de mevcuttur. Kim olursa olsun, içerideki düşman her yerde köksüz, vahşi, tembel, suça ve devleti sömürmeye yatkın olarak temsil edilir. Üzülerek söylüyorum ki; 2011'de Sarkozy Fransa'daki Doğu Avrupalı göçmenlerin kamplarını dağıttığında yaptığı şey biz ve onlar, vatandaşlar ve yabancılar arasındaki sınırı yeniden çizmekten başka bir şey değildi. Bunun adı düşman tarif ederek yeniden toplumsal birlik yaratmaktır. Türkiye'de iç düşmanlar dini, etnik ve bölgesel unsurlar içerecektir. Kürtler, Ermeniler, Aleviler gibi kesimler suça ve başkaldırmaya yatkın olarak temsil edilirler; meydanlara çıktıklarında bu siyasal eylem olarak değil, devlete meydan okuma olarak görülür. Dolayisıyla, esasen sivil, toplumsal, dini ya da etnik kökenli talepler suçlulaştırılarak biz ve onlar, halk ve düşmanlar arasındaki sınırlar yeniden çizilmiş olur. Böylelikle, ceza aygıtı aracılığıyla Carl Schmitt problemi de çözüme kavuşmuş olur. Kısaca özetlemek gerekirse, yeni kentsel marjinalliğin ürettiği açmazlar neoliberal devlet için inşa zemini oluştururken; devletin polis, mahkeme, hapishane gibi cezalandırıcı kanadının etkinleştirilmesiyle de sözünü ettiğimiz açmazlar çözüme kavuşturulmuş olur.

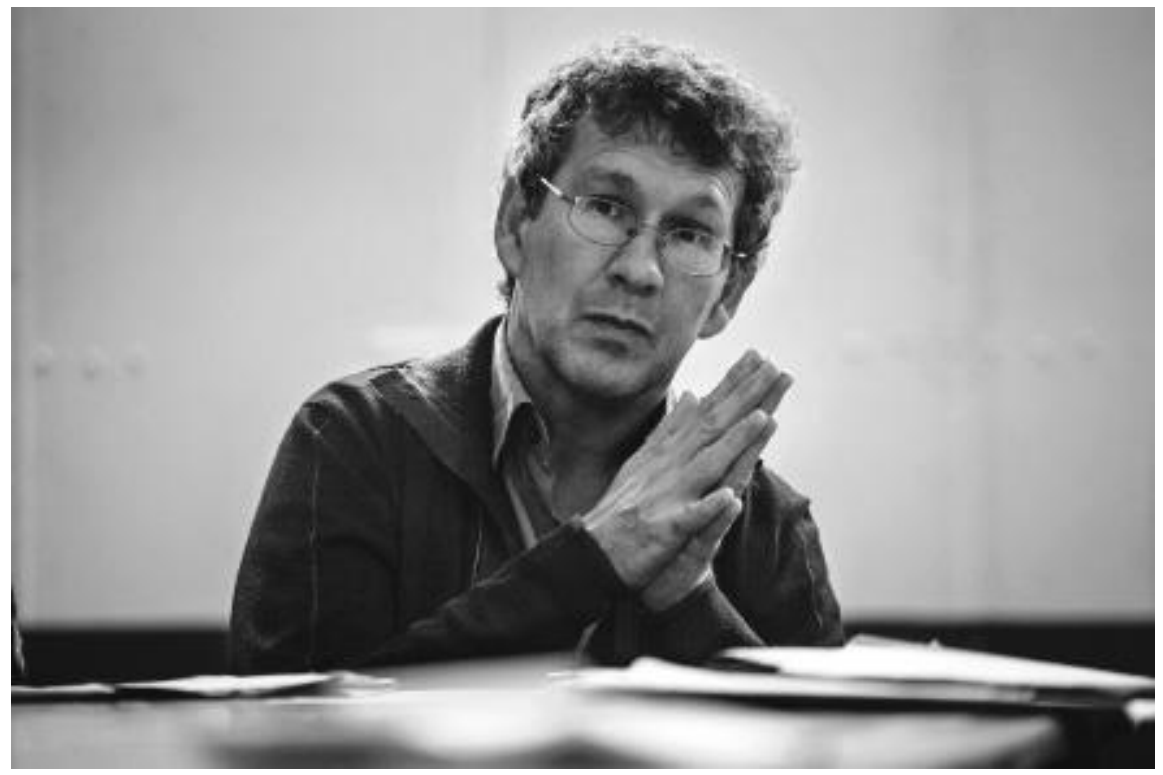


AA: Galatasaray Üniversitesi'ndeki konuşmanızda Bourdieu'nün teorisinde vazgeçilmez iki unsur olarak, sembolik iktidar ve toplumsal uzamın önemini vurguladını. Kent Paryaları'nda incelediğiniz fiziksel uzamın bu iki temel unsurla ilişkisi nedir? Aralarında bir örtüşmeden söz edebilir miyiz?

LW: Kent ve Bölge Araştırmaları Dergisi'nin (Journal of Urban and Regional Research) Bourdieu özel sayısı için yazmakta olduğum makalede, Bourdieu'nün teorisinin kent sosyolojisini hem yeniden inşa etmek hem de feshetmek için güçlü ve yaratıcı araçlar sunduğunu ileri sürüyorum (Wacquant, 2018). Sembolik, toplumsal ve fiziksel uzamlar arasındaki ilişkiyi incelemek bir yeniden inşa olanağ sunar. Fiziksel uzam bir anlamda, sembolik ve toplumsal uzamlarda kaynaklara erişmek için verilen mücadelelerin somutlaşmış halidir. Dolayısıyla bu üçlü ilişkiyi incelemek, kent sosyolojisini yeniden inşa etmek için titiz bir temel sunabilir. Kent sosyolojisine özgü sorunlardan biri, kavramın tanımlanmasında yaşanan zorluktur. Kent sosyolojisi dediğimizde neyi kast ediyoruz? Belirli bir kurum olarak kentin sosyolojisini mi, yoksa kapitalizm, metalaşma ve toplumsal cinsiyet ilişkileri gibi kentte olan her şeyin sosyolojisini mi? Başka bir şekilde soracak olursak, kentin sosyolojisini mi, kentteki sosyolojiyi mi ima ediyoruz? Kendisini kent sosyoloğu olarak adlandıranların çoğu, aslında kenti çalışmıyor; kentteki toplumsal cinsiyeti ya da siyaseti çalışıyor. Dolayısıyla Bourdieu'nün kavram setine başvurarak, kent sosyolojisi kente özgü olmayan, kırda da gözlemlenebilen, bir mekân sosyolojisidir sonucuna da ulaşabiliriz. Böylelikle kent sosyolojisini feshedip, topolojik sosyolojinin alt başlığına dönüştürmüş oluruz.

Fakat Bourdieu'nün kavram seti bize, kenti kendine özgü bir ortam olarak yeniden düşünme olanağı da sunar. Benzer bir çabayı sergileyen iki geleneksel akımdan söz edebiliriz. Bunlardan ilki, kenti kendine has kapsama alanı ve nüfus yoğunluğu gibi özellikler barındıran bir mekân olarak gören Chicago Okulu'dur. Fakat kentin bu özelliklerini kesin bir açıklığa kavuşturmadığı için bu yaklaşım muğlak olarak kalır. İkinci yaklaşım ise David Harvey ve erken dönem Manuel Castells'in çalışmalarını içeren neo-Marxist yaklaşımdır. Harvey'e göre kent, sermayenin arazi spekülasyonları etrafında yeniden devreye girdiği ikinci dolaşım uzamıdır. Castells'e göre ise kent, kolektif tüketimin mekânıdır. Fakat bu yaklaşımların hiçbiri yeterince açıklayıcı değildir. Weber ve Bourdieu'yü birlikte ele alarak, kenti göreceli değerlerini belirlemek için mücadele halinde bulunan farklı sermaye türlerini barındıran mekân olarak tanımlayabiliriz. Öyleyse kent, sermaye türlerinin yoğunlaştı̆̆ı, biriktiği ve 
farklılaştığı bir mekândır. Böyle bir Bourdieu okuması kent sosyolojisini feshetmek yerine, onu yeni bir kent kavrayışı üzerinden kurmayı mümkün kılar.

AA: Bu kent kavrayışı üzerinden Gezi olaylarını nasıl açıklayabiliriz? Çalışmanızda incelediğiniz hipergetto ve banliyö failleriyle karşılaştırdığınızda, Gezi'nin faillerini nasıl tanımlarsinız?

LW: Gezi'yi, mekânı kendi hayat imkânlarını, özellikle de kültürel sermayelerini, değerlendirmek için kullanmak isteyen küçük kültür burjuvazisinin öncülük ettiği kent eylemlerinin erken bir işareti olarak görüyorum. Gezi, kenti eski usullere göre yönetmek isteyen otoritelere karş1 tepki eylemiydi. Kenti, hayat imkânlarının gerçekleştirileceği bir tüketim mekânı olarak gören kültürel sermaye sahipleri yeni bir kent yönetimi talep ediyordu. Mısır, İspanya, Brezilya ve Türkiye'deki eylemleri birlikte ele aldığımızda, meydandakilerin kültürel olarak donanımlı ama ekonomik olarak dışlanmış, işsiz genç kesimler olduğunu görüyoruz. Kültürel sermayeye ve seslerini duyurma imkânına sahipler. Çalışmamda incelediğim kent paryalarıyla hiçbir benzerlikleri yok. Gezi'yi yeni kültür burjuvazisiyle prekaryayı ilişkilendirme imkânı da barındıran, kentin kendi tüketimleri için yeniden inşa edilmesini talep edenlerin karmaşık bir hareketi olarak görüyorum. Eylemlere katılan arkadaşlarımla tartıştığımızda, Gezi hakkındaki görüşlerimden hoşlanmadıklarını görüyorum. Onlara, eylemlerden önce parkın sakinlerinin alt sinıflar, özellikle de alt sınıf eşcinseller, olduğunu, fakat kentsel mekânın ticarileşmesine karşı olanların, parkı eğitimli orta sınıflar için talep ettiğini anlatıyorum. Kısaca ifade etmek gerekirse, Gezi'yi hem devleti, hem de parkın marjinalleşmiş alt sınıf kullanıcılarını karşısına alan, dipten gelen bir soylulaştırma mücadelesi olarak görüyorum. Gezi muğlak bir hareket: Bir yanıla ilerici; devletin daha demokratik, daha kapsayıcı, kültürel çeşitliliklere daha saygılı olmasını talep ediyor; bir yanıyla da muhafazakâr; çünkü parkın önceki kullanıcılarını marjinalleştiriyor.

Çeviri: Aksu Akçaoğlu 


\section{Kaynakça}

Bourdieu, P. (1991). Political representation: Elements for a theory of political field. in Bourdieu, P. Language and symbolic power. Cambridge: Polity Press.

Fraser, N. (2013). Fortunes of feminism: From state-managed capitalism to neoliberal crisis. New York: Verso.

Polanyi, K. (2000) Büyük dönüşüm: Çağımızın siyasal ve ekonomik kökenleri. İstanbul: İletişim Yayınları.

Schmitt, C. (2007). The concept of the political. Chicago: The University of Chicago Press.

Wacquant, L. (2018). "Bourdieu Comes to Town: Pertinence, Principles, Applications." International Journal of Urban and Regional Research 4 (1): 90-105.

Loïc Wacquant Berkeley'deki California Üniversitesi kampüsünde sosyoloji profesörü ve Paris'teki Avrupa Sosyoloji Merkezi'nde araştırmacıdır. Temel ilgi alanları, kentsel marjinallik, ceza, bedensellik ve toplum kuramıdır. MacArthur Ödülü'nü kazanan Wacquant'ın yirmiden fazla dile tercüme edilmiş kitaplarından bazıları şunlardır: Body and Soul: Notebooks of An Apprentice Boxer (2004, yeni genişletilmiş baski, 2016), The Two Faces of the Ghetto (2016), ve Tracking the Penal State (2016). Daha fazla bilgi için yazarın kişisel internet sitesi olan loicwacquant.net'i ziyaret edebilirsiniz.

Loï Wacquant is professor of sociology at the University of California, Berkeley, and researcher at the Centre de sociologie européenne, Paris. His interests include urban marginality, penality, carnality, and social theory. A MacArthur Prize Fellow, his books have been translated in two dozen languages and include Body and Soul: Notebooks of An Apprentice Boxer (2004, new expanded edition, 2016), The Two Faces of the Ghetto (2016), and Tracking the Penal State (2016). For more information, see loicwacquant.net.

Aksu Akçaoğlu İstanbul Üniversitesi Halkla İlişkiler ve Tanıtım bölümünden 2004'te mezun oldu. Yüksek Lisans ve doktora derecelerini Orta Doğu Teknik Üniversitesi Sosyoloji Bölümü'nden aldı. Halen Çanakkale Onsekiz Mart Üniversitesi Sosyoloji Bölümü'nün akademik kadrosundadır.

Aksu Akçaoğlu graduated from Public Relations and Advertising Department of Istanbul University in 2004. He accomplished the MSc and PhD degrees on Sociology from Middle East Technical University. He is currently a faculty member at the Sociology Department of Çanakkale Onsekiz Mart University. 